\title{
Decision Tree Learning Approach To Wildfire Modeling on Peat and Non-Peat Land in Riau Province
}

\author{
Muchamad Taufiq Anwar, Hindriyanto Dwi Purnomo, Sri Yulianto Joko Prasetyo*, Kristoko Dwi \\ Hartomo \\ Faculty of Information Technology \\ Satya Wacana Christian University \\ Salatiga, Indonesia \\ taufiq.anwar.m@gmail.com, hindriyanto.purnomo@staff.uksw.edu, sri.yulianto@staff.uksw.edu, \\ kristoko@uksw.edu
}

\begin{abstract}
Wildfire is one of the most frequent disasters occurred in Indonesia and had caused tremendous economic loss, environmental damage, and endangered the life of human and other organisms. Wildfire cases happened in Indonesia are occurred on both peat and mineral (non-peat) land. However, the number of research on wildfire modeling which includes peat land is very limited. This research aims to build a wildfire model based on decision tree learning which includes peatland as the factor contributing to wildfire. This will also provide an alternative model for the current national risk index which is based on additive weighting. This model then can be used to build an early warning/risk map which is very useful in managing / mitigating wildfire to minimize loss. We use C4.5 classification algorithm to build the model, and exploring the contribution of each attribute to the model. Factors used in this study are the land type (peat or mineral), land cover/ land use, Normalized Difference Vegetation Index (NDVI), and The Normalized Difference Moisture (Water) Index (NDMI). The result showed that the most prominent factor in wildfire cases in our study area is the peatland, followed by its combination with land use types. While the NDVI and NDMI have a very little contribution to the model. The model with all factors included has the accuracy of $78 \%$. The implication of this result is then discussed.
\end{abstract}

Keywords-wildfire model; peatland; decision tree; 